\title{
Baicalein induces apoptosis of human cervical cancer HeLa cells in vitro
}

\author{
YONG PENG ${ }^{1}$, CONGSHAN GUO $^{1}$, YANHONG YANG ${ }^{2}$, FENGLIN LI $^{3}$, \\ YANXIA ZHANG ${ }^{1}$, BIN JIANG ${ }^{1}$ and QINGWANG LI ${ }^{4}$ \\ ${ }^{1}$ Department of Biomedical Engineering, College of Electrical Engineering, Yanshan University, Qinhuangdao, Hebei 066004; \\ ${ }^{2}$ Department of Oncology, The First Hospital of Qinhuangdao Town, Qinhuangdao, Hebei 066003; ${ }^{3}$ Department of \\ Bioengineering, Jilin Agricultural Science and Technology College, Jilin 132101; ${ }^{4}$ College of Animal Science and Technology, \\ Northwest Agriculture and Forestry University, Yangling, Shanxi 712100, P.R. China
}

Received December 16, 2013; Accepted June 17, 2014

DOI: $10.3892 / \mathrm{mmr} .2014 .2885$

\begin{abstract}
A number of studies have shown that baicalein shows high antitumor activity in vitro and in vivo. In this study, the inhibitory effect of baicalein on human cervical cancer HeLa cells was studied in vitro. HeLa cells were treated with high $(100 \mu \mathrm{g} / \mathrm{ml})$ and low $(50 \mu \mathrm{g} / \mathrm{ml})$ doses of baicalein, and cell growth inhibition rates were examined by the MTT assay. The morphological changes of apoptotic cells were observed under the light and electron microscope, while the rate of cell apoptosis was examined by flow cytometry. The expression of apoptosis-related proteins was analyzed by western blot, and caspase- 3 activation was examined by a caspase- 3 activity assay and spectrophotometry. The results demonstrated that baicalein inhibits the proliferation of HeLa cells and induces apoptosis in a caspase-3-dependent pathway, through downregulation of the $\mathrm{B}$-cell lymphoma $2(\mathrm{Bcl}-2)$ protein and upregulation of the Bcl-2-associated X protein (Bax), Fas, Fas ligand (FasL) and caspase-8. Thus, we conclude that baicalein induces apoptosis of HeLa cells via the mitochondrial and the death receptor pathways. Cell apoptosis in HeLa cells was most likely promoted by the activation of the proteolytic enzyme caspase- 3 in both pathways.
\end{abstract}

\section{Introduction}

Carcinoma of the uterine cervix is the second most common malignancy in women, the morbidity of which is only lower than that of breast cancer worldwide, while this type of cancer is the most prevalent in certain developing countries (1). Currently, surgery, chemotherapy and radiotherapy are the most commonly adopted strategies to treat cervical cancer.

Correspondence to: Dr Yong Peng, Department of Biomedical Engineering, College of Electrical Engineering, Yanshan University, No. 438 Hebei Street, Haigang, Qinhuangdao, Hebei 066004, P.R. China

E-mail:py81@sina.com

Key words: baicalein, HeLa cells, apoptosis, mitochondrial pathway, death receptor pathway, caspase-3
Adjuvant radiotherapy or chemotherapy following tumor resection aim to inhibit the proliferation of tumor cells, but the biggest drawback of this therapy is that healthy cells are also killed, which may cause serious complications. In recent years, numerous studies have been carried out to investigate the potential anticancer properties of natural products, which are considered as non-toxic and thus may have fewer sideeffects than synthetic drugs (2). The potential of natural products from medicinal plants used in prevention and treatment of cancer has been recognized by the scientific community. Traditional Chinese medicine and its active ingredients can contribute in cancer treatment via a variety of mechanisms, including induction of apoptosis (3), inhibition of telomerase activity (4), inhibition of angiogenesis (5), improvement of immune functions, cytotoxicity, etc. The majority of studies focusing on antitumor agents aim for the shrinkage or the disappearance of the tumor, by inducing cancer cell apoptosis.

Scutellaria baicalensis Georgi, included in Chinese pharmacopoeia, has a long history of use as a traditional Chinese medicinal plant, and contains a variety of flavonoid compounds. Among these, the most active component is baicalein. In recent years, numerous studies reported multiple pharmacological activities for baicalein, including anticancer properties. So far, the anticancer effects of baicalein have been widely explored on breast cancer (6), hepatoma (7), skin carcinoma (8), pancreas cancer (9), and lung squamous carcinoma (10). Baicalein appears to inhibit cell growth and induce cell apoptosis via several pathways. We previously investigated the anticancer effect of baicalein by establishing mice tumor models of U14 cervical cancer, and the results showed that baicalein inhibits the growth of U14 cervical cancer cells, and that it can induce cell apoptosis by downregulating the expression of the B-cell lymphoma 2 (Bcl-2) protein and by upregulating the Bcl-2-associated X protein (Bax) (11).

In the present study, human cervical cancer HeLa cells were further used to test the anticancer effect of baicalein in vitro. The effect of baicalein treatment on proliferation of HeLa cells was determined by the MTT assay. We explored whether baicalein can induce HeLa cell apoptosis by flow cytometry and morphological observations of the cells. The 
expression of apoptosis-related proteins was measured by western blotting and spectrophotometric methods, in order to investigate the underlying mechanisms of baicalein-induced apoptosis in cervical cancer HeLa cells.

\section{Materials and methods}

Chemicals and reagents. Baicalein was purchased from Nanjing ZeLang Medical Technology Co., Ltd. (product no., ZL100708; Nanjing, Jiangsu, China), and the determined purity was $98.71 \%$. Dulbecco's modified Eagle's medium (DMEM) was purchased from Thermo Fisher Scientific (Waltham, MA, USA). Superior-grade fetal bovine serum (FBS) and the Annexin V-FITC Apoptosis Detection kit were obtained from KeyGen Biotech. Co., Ltd. (Nanjing, Jiangsu, China). The MTT cell proliferation kit, the caspase-3 activity assay kit, the bicinchoninic acid (BCA) protein assay kit, dimethyl sulfoxide (DMSO), trypsin-EDTA solution, protein molecular weight marker, cell lysis buffer for western and horseradish peroxidase (HRP)-labeled goat anti-rabbit $\operatorname{IgG}(\mathrm{H}+\mathrm{L})$ and polyvinylidene fluoride (PVDF) membranes were purchased from the Beyotime Institute of Biotechnology (Shanghai, China). Rabbit anti-Bcl-2, -Bax, -Fas, -Fas ligand (FasL), -caspase- 8 and - $\beta$-actin were purchased from Beijing Biosynthesis Biotechnology Co., Ltd. (Beijing, China). All other chemicals used were of analytical grade.

Cell cultures. The human cervical carcinoma HeLa cell line was obtained from the Tumor Hospital of the Chinese Academy of Medical Sciences. HeLa cells were cultured in DMEM supplemented with 10\% FBS, penicillin $(100 \mu / \mathrm{ml})$ and streptomycin $(100 \mu / \mathrm{ml})$. HeLa cell cultures were maintained at $37^{\circ} \mathrm{C}$ in an atmosphere of $95 \%$ humidified air and 5\% $\mathrm{CO}_{2}$. Cells were passaged every 2-3 days.

Drug preparation. Baicalein was first dissolved in DMSO as a stock solution, and then diluted with DMEM. The study design comprised three groups: control, baicalein high-dose $(100 \mu \mathrm{g} / \mathrm{ml})-$ and low-dose $(50 \mu \mathrm{g} / \mathrm{ml})$-treated group. The baicalein solution was added into HeLa cells cultured for $24 \mathrm{~h}$, while the same volume of medium was added to the control group.

MTT assay. HeLa cells were seeded in 96-well plates at a density of $5 \times 10^{3}$ cells/well and cultured for $24 \mathrm{~h}$. Following cell treatment with different concentrations of baicalein $(25$, $50,75,100,150$ and $200 \mu \mathrm{g} / \mathrm{ml}$ ) for $24 \mathrm{~h}, 10 \mu \mathrm{l}$ MTT solution $(5 \mathrm{mg} / \mathrm{ml})$ were added into each well and incubated with cells for $4 \mathrm{~h}$ at $37^{\circ} \mathrm{C}$. Then, DMSO was added for $4 \mathrm{~h}$ to dissolve the formazan crystals. Finally, the optical density (OD) at $570 \mathrm{~nm}$ was measured using a microplate reader, and the inhibition rate (IR) was calculated according to the following formula:

$$
\operatorname{IR}(\%)=\left(1-\mathrm{OD}_{\text {treated }} / \mathrm{OD}_{\text {control }}\right) \times 100 \%
$$

The half maximal inhibitory concentration $\left(\mathrm{IC}_{50}\right)$ value was calculated by regression curve analysis of IR values at different concentrations.
Table I. Effect of baicalein on growth of HeLa cells.

\begin{tabular}{lcc}
\hline Group & Optical density $^{\mathrm{a}}$ & Inhibition rate $(\%)$ \\
\hline Control & $1.03 \pm 0.09$ & - \\
Baicalein $(25 \mu \mathrm{g} / \mathrm{ml})$ & $0.87 \pm 0.05^{\mathrm{b}}$ & 15.53 \\
Baicalein $(50 \mu \mathrm{g} / \mathrm{ml})$ & $0.72 \pm 0.04^{\mathrm{b}}$ & 30.10 \\
Baicalein $(75 \mu \mathrm{g} / \mathrm{ml})$ & $0.59 \pm 0.03^{\mathrm{b}}$ & 42.72 \\
Baicalein $(100 \mu \mathrm{g} / \mathrm{ml})$ & $0.51 \pm 0.03^{\mathrm{c}}$ & 50.49 \\
Baicalein $(150 \mu \mathrm{g} / \mathrm{ml})$ & $0.38 \pm 0.02^{\mathrm{c}}$ & 63.11 \\
Baicalein $(200 \mu \mathrm{g} / \mathrm{ml})$ & $0.31 \pm 0.01^{\mathrm{b}}$ & 69.90 \\
\hline
\end{tabular}

${ }^{\mathrm{a}}$ mean $\pm \mathrm{SD}(\mathrm{n}=10) ;{ }^{b} \mathrm{P}<0.05,{ }^{\mathrm{c}} \mathrm{P}<0.01$ as compared to the control group.

Cell morphological assessment. After culturing for $24 \mathrm{~h}$, HeLa cells were treated with high and low doses of baicalein. Changes in cell morphology were examined under an inverted microscope (TS100; Nikon, Tokyo, Japan) at 24 and 48 h. After treatment for $48 \mathrm{~h}$, the cells were collected and fixed using $2.5 \%$ glutaraldehyde at $4^{\circ} \mathrm{C}$. Then, the cells were post-fixed in $1 \%$ osmium tetroxide at room temperature, dehydrated in a gradient of acetone and embedded in epoxy resin. Ultrathin sections were stained with lead citrate and uranyl acetate, prior to examination under a transmission electron microscope (JEM-1200EX; JEOL Ltd., Tokyo, Japan).

Flow cytometry analysis. HeLa cells were collected after baicalein treatment for $48 \mathrm{~h}$, and were washed twice using PBS. To prepare single-cell suspensions, cells were filtered through a 300-mesh strainer (Thermo Fisher Scientific). Cells $\left(1 \times 10^{6}\right)$ were counted and resuspended in $500 \mu \mathrm{l}$ binding buffer solution. Subsequently, $5 \mu 1$ Annexin V-FITC and $5 \mu \mathrm{l}$ propidium iodide (PI) were added, and the mixture was incubated for $10 \mathrm{~min}$ in the dark. Finally, cells were analyzed in a FACSCalibur flow cytometer (BD Biosciences, Franklin Lakes, NJ, USA), and the cell apoptotic rates were analyzed with the ModFIT software (Verity Software House, Topsham, ME, USA).

Western blot analysis. After $48 \mathrm{~h}, \mathrm{HeLa}$ cells treated with baicalein were washed twice with cold PBS and lysed in cell lysis buffer. Protein concentrations were determined by the BCA method. Next, equivalent amounts of protein were separated by sodium dodecyl sulfate polyacrylamide gel electrophoresis and transferred onto PVDF membranes. After blocking with $5 \%$ non-fat milk overnight at $4{ }^{\circ} \mathrm{C}$, the membranes were incubated with anti-Bcl-2, -Bax, -Fas, -FasL, -caspase- 8 and $-\beta$-actin antibodies. Subsequently, membranes were washed and incubated with HRP-conjugated goat ant-rabbit IgG as the secondary antibody. Finally, protein bands were detected using an enhanced chemiluminescence kit (ECL; BestBio, Inc., Shanghai, China).

Caspase-3 activity assay. Cells were incubated in DMEM and treated with 50 and $100 \mu \mathrm{g} / \mathrm{ml}$ baicalein for $12,24,36$ and $48 \mathrm{~h}$. Cells $\left(5 \times 10^{6}\right)$ were harvested and washed with PBS. Following cell lysis on ice, the supernatant was collected, and the protein 


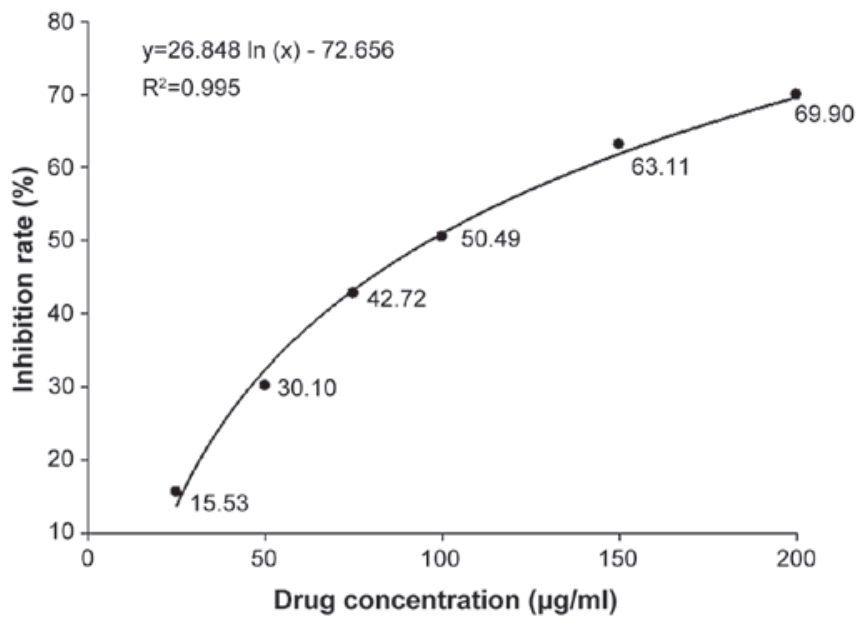

Figure 1. Effect of baicalein on the growth of HeLa cells.

concentration was measured using the BCA method. We added $2 \mathrm{X}$ reaction buffer and caspase- 3 substrate into the lysis buffer containing $200 \mu \mathrm{g}$ of total protein, while the control group contained only lysis buffer and $2 \mathrm{X}$ reaction buffer. Following incubation at $37^{\circ} \mathrm{C}$ for $4 \mathrm{~h}$ in dark, the OD was measured on a microplate reader (Multiskan MK3; Thermo Fisher Scientific) at $450 \mathrm{~nm}$, and the caspase-3 activity was calculated as the value $\mathrm{OD}_{\text {treated }} / \mathrm{OD}_{\text {control }}$.

Statistical analysis. Statistical analysis was performed by one-way analysis of variance, and differences between means were tested using Duncan's multiple range tests. The data were expressed as mean $\pm \mathrm{SD}$. P-values $<0.05$ were considered to indicate statistically significant differences. The software SPSS 13.0 (SPSS Inc., Chicago, IL, USA) was used for data processing.

\section{Results}

Effect of baicalein on the growth of HeLa cells. The growth inhibition of HeLa cells was determined by the MTT assay. Following treatment with baicalein for $24 \mathrm{~h}$, the inhibition rates of HeLa cells were calculated (Table I). The results showed that baicalein significantly inhibits proliferation of HeLa cells, and in a dose-dependent manner $(\mathrm{P}<0.05, \mathrm{P}<0.01)$. The $\mathrm{IC}_{50}$ of baicalein $(24 \mathrm{~h})$, calculated by regression curve analysis, was $96.51 \mu \mathrm{g} / \mathrm{ml}$ (Fig. 1).

Observation of morphological features of HeLa cell apoptosis under the light microscope. The features of untreated HeLa cells were as follows: cells grew well, were polygonal in shape, with uniform colors and loose chromatin. After treatment with high and low doses of baicalein for 24 and $48 \mathrm{~h}$, some cells became shrank and round, and then detached from the culture dish and floated into the medium. The edge of apoptotic cells was black, and an increasing number of black particles within the cells was observed. Moreover, part of the cell membrane protruded, and apoptotic bodies eventually appeared. With the enhancement of baicalein dose and treatment time, the number of apoptotic cells increased (Fig. 2).

Observation of morphological features of HeLa cell apoptosis by electron microscopy. Morphological and ultrastructural features of HeLa cells were analyzed by transmission electron microscopy (TEM). In the control group, the cell surface
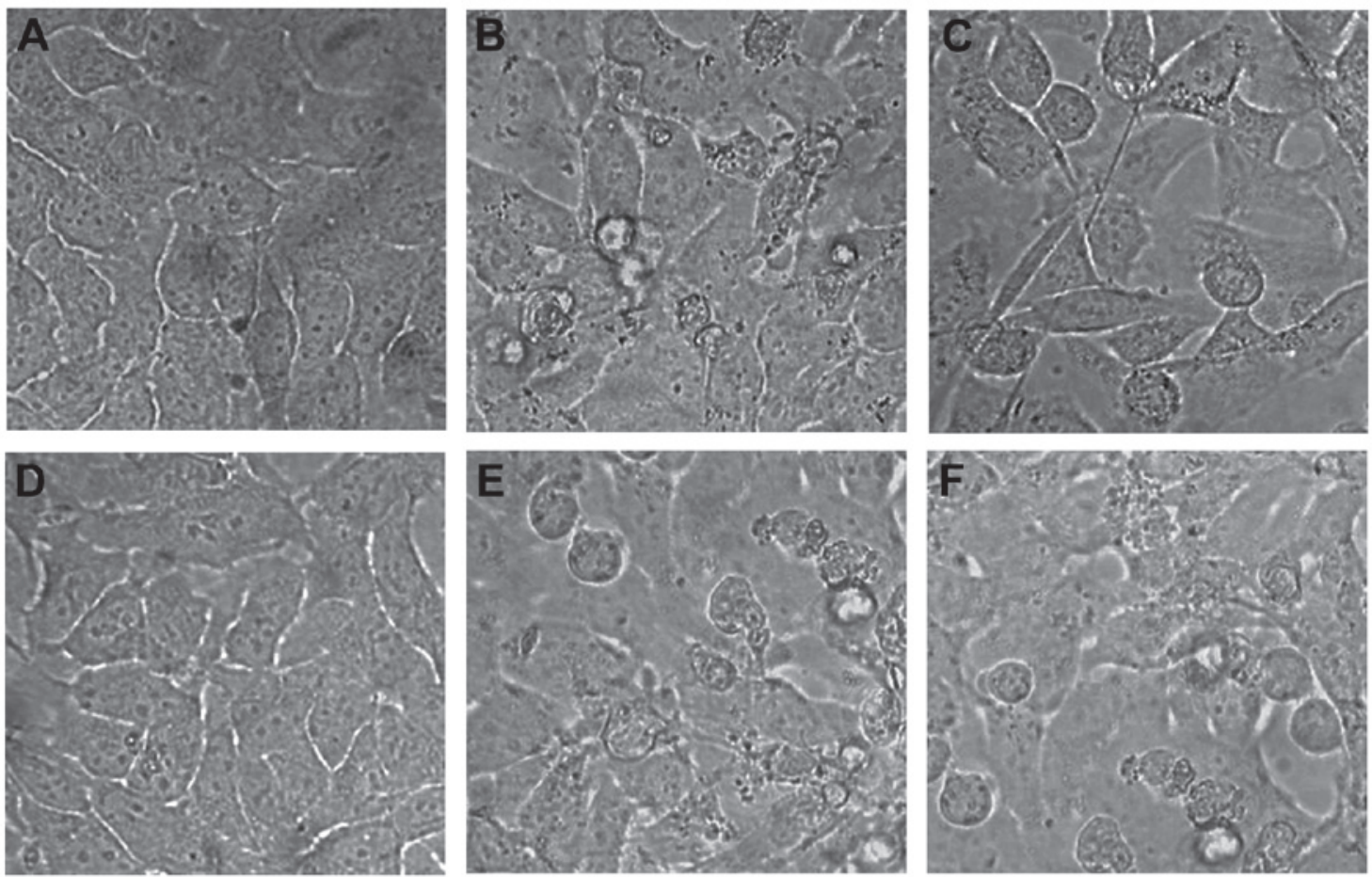

Figure 2. Morphological changes in apoptotic HeLa cells induced by baicalein, as observed under a light microscope (magnification, $\mathrm{x} 400$ ). (A) Control group at $24 \mathrm{~h},(\mathrm{~B})$ high-dose baicalein group at $24 \mathrm{~h},(\mathrm{C})$ low-dose baicalein group at $24 \mathrm{~h}$, (D) control group at $48 \mathrm{~h},(\mathrm{E}) \mathrm{high}$-dose baicalein group at $48 \mathrm{~h},(\mathrm{~F})$ lowdose baicalein group at $48 \mathrm{~h}$. 

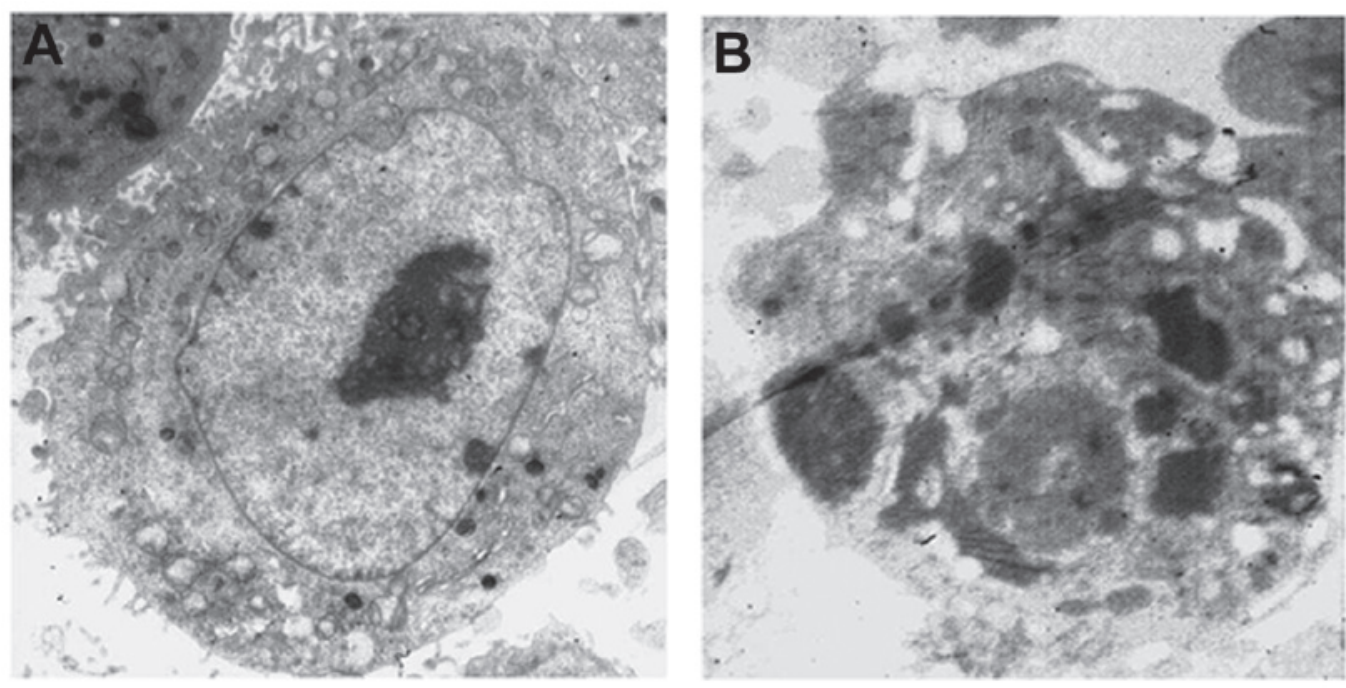

Figure 3. Morphological changes in apoptotic HeLa cells induced by baicalein, as observed by transmission electron microscopy (magnification, x6,000). (A) Control group, (B) high-dose baicalein group.
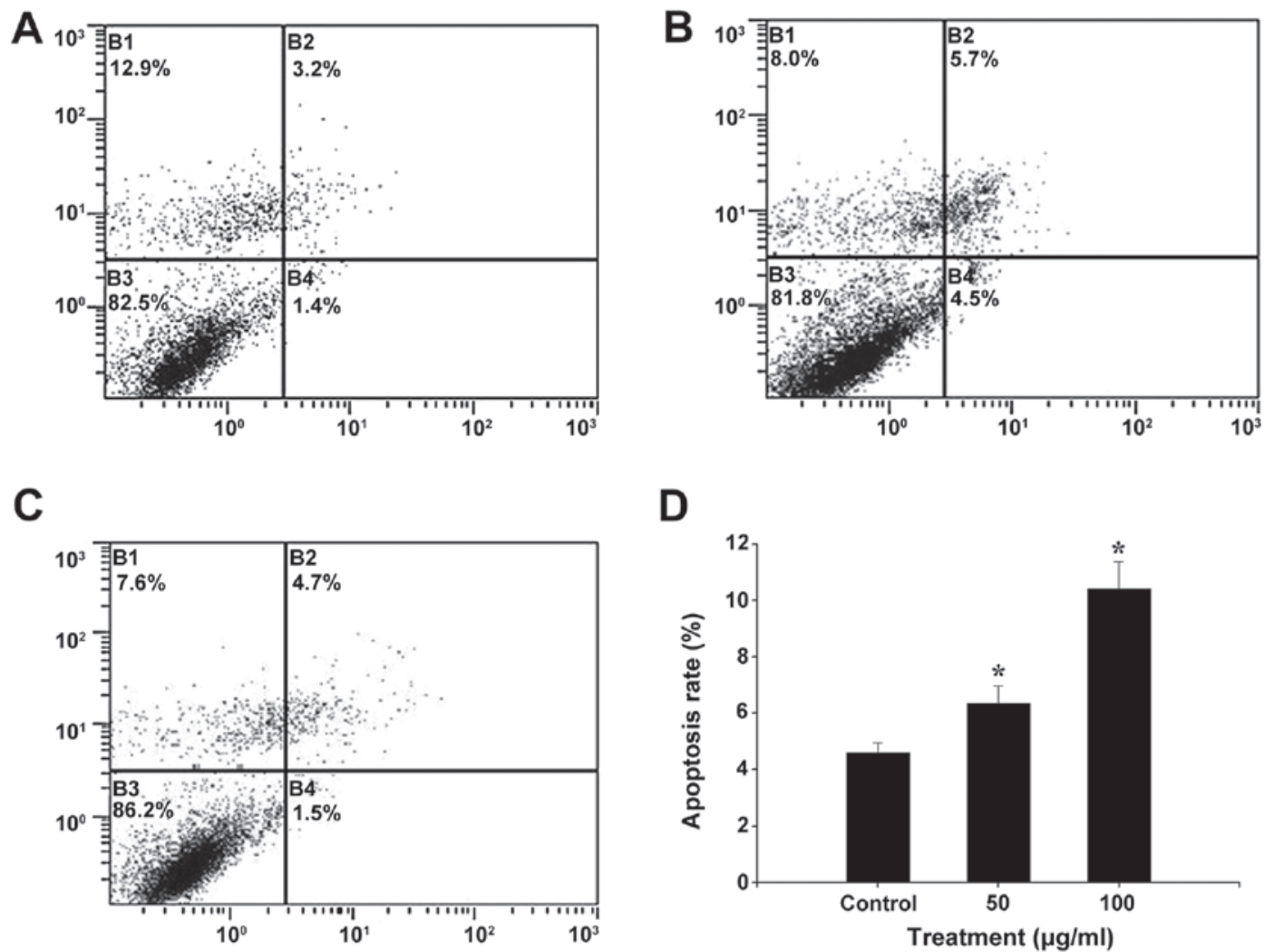

Figure 4. Induction of apoptosis by baicalein in HeLa cells, detected by flow cytometry. (A) Control, (B) high-dose baicalein, and (C) low-dose baicalein groups. (D) Quantified results of flow cytometry. Bars represent mean apoptotic rate $\% \pm \mathrm{SD}(\mathrm{n}=10)$; ${ }^{*} \mathrm{P}<0.05$ as compared to the control group.

was full of microvilli, and within the cell, organelles such as mitochondria, rough surfaced endoplasmic reticulum etc. were observed. Moreover, the cell nuclei were large, with loose chromatin and a prominent central nucleolus. When HeLa cells were treated with high-dose baicalein for $48 \mathrm{~h}$, the number of apoptotic cells markedly increased. A number of typical features of apoptosis were observed: plasma membrane blebbing, chromatin condensation, increased cell density, mitochondria with vacuoles, karyorrhexis and formation of apoptotic bodies (Fig. 3).
Assessment of the percentage of apoptotic cells by double staining and flow cytometry. Following cell exposure to baicalein for $48 \mathrm{~h}$, the apoptotic rates were determined by Annexin V-FITC/PI staining and flow cytometry. HeLa cells were classified into four states: viable cells (Fig. 4, B3 quadrant, Annexin-/PI), early apoptotic cells (B4 quadrant, Annexin ${ }^{+} / \mathrm{PI}$ ), late apoptotic cells (B2 quadrant, Annexin ${ }^{+} / \mathrm{PI}^{+}$), and necrotic cells (B1 quadrant, Annexin $/ \mathrm{PI}^{+}$). Our results showed that baicalein treatment significantly enhances 


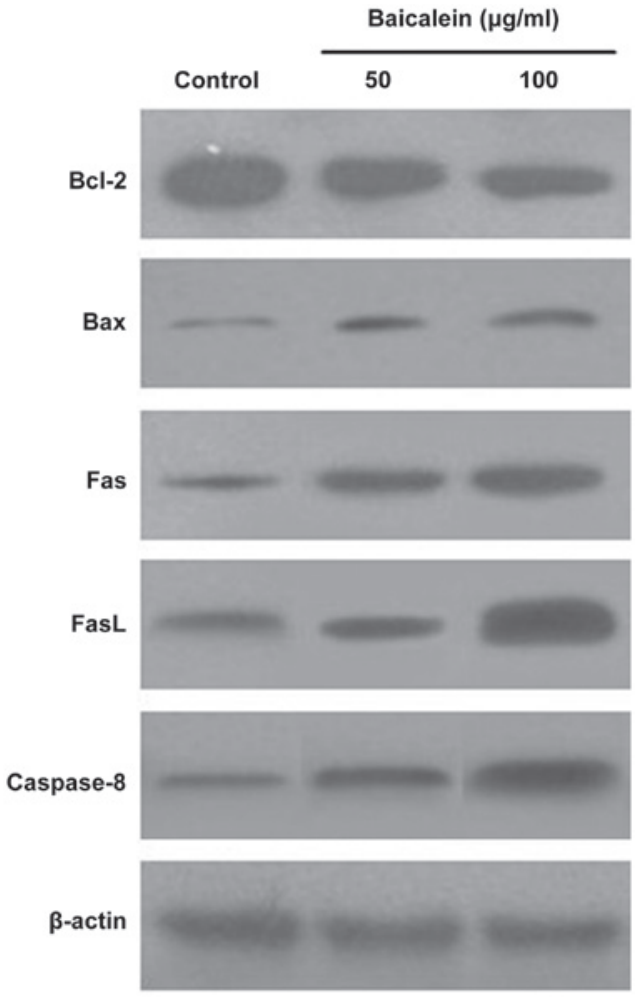

Figure 5. Protein expression of B-cell lymphoma 2 (Bcl-2), Bcl-2-associated $\mathrm{X}$ protein (Bax), Fas, Fas ligand (FasL), caspase- 8 and $\beta$-actin following baicalein treatment in HeLa cells.

apoptosis of HeLa cells, with an apoptotic rate estimated at $10.42 \pm 0.96 \%$ in the high-dose baicalein group, $6.36 \pm 0.62 \%$ in the low-dose baicalein group, and $4.61 \pm 0.34 \%$ in the control group, suggesting that baicalein can induce HeLa cell apoptosis in a dose-dependent manner.

Expression of apoptosis-related gene products examined by western blot analysis. Western blot results showed that compared to the control group, the expression of Bcl-2 was decreased upon baicalein treatment, with its expression level in the high-dose treatment group being lower compared to the low-dose treatment group. By contrast, the expression of Bax, Fas, FasL and caspase- 8 increased with the increase in the baicalein dose. The $\beta$-actin protein expression level was not affected by baicalein treatment, therefore $\beta$-actin was considered a suitable internal loading control (Fig. 5).

Activation of caspase-3 examined by a spectrophotometric method. Following treatment with baicalein for 12, 24, 36 and $48 \mathrm{~h}$, the caspase- 3 activity of HeLa cells was measured using a caspase-3 assay kit and spectrophotometry. The results showed that with the increase in treatment time, the caspase- 3 enzyme was gradually activated, while the caspase- 3 activity of cells in the control group did not significantly change. The caspase-3 activity did not prominently increase after $12 \mathrm{~h}$, but after 24 , 36 and $48 \mathrm{~h}$ of treatment, it was significantly enhanced in both the low-and high-dose treatment groups $(\mathrm{P}<0.05, \mathrm{P}<0.01)$. The rate of caspase- 3 activation in the high-dose group was faster compared to the low-dose group, which indicated that baicalein induces the activation of caspase- 3 in a time- and dose-dependent manner (Fig. 6).

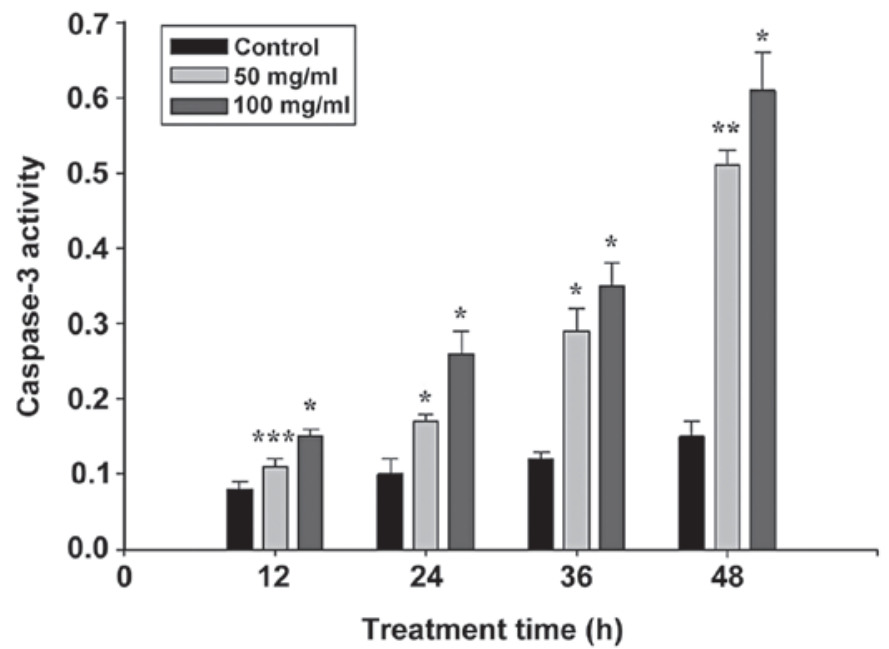

Figure 6. Effect of baicalein on caspase-3 activity in HeLa cells. Bars represent mean activity $\pm \mathrm{SD}(\mathrm{n}=10) ;{ }^{*} \mathrm{P}<0.05,{ }^{* *} \mathrm{P}<0.01,{ }^{* * * *} \mathrm{P}>0.05$ compared to the control group.

\section{Discussion}

Cell apoptosis is a major form of programmed cell death, which plays an important role in regulating growth and development of multi-cellular organisms, by maintaining the stability of cells. In cancer biology, it is now evident that numerous cancer cells circumvent the normal apoptotic mechanisms to prevent their self-destruction, and thus, apoptosis has become an attractive focus in life-science research (12). The regulation of apoptosis is a very complex process, with multiple genes and proteins involved, including pro- and anti-apoptotic proteins, death receptors and ligands (e.g., Fas and FasL), caspases etc. Based on current knowledge on apoptosis, this process is mainly induced by two pathways, the mitochondrial (intrinsic) and the cell-death receptor (extrinsic) pathway, and the two pathways are linked (13).

One of the major hallmarks of anticancer activity is the ability of drugs to inhibit growth of cells. The MTT assay results showed that baicalein inhibits the growth of $\mathrm{HeLa}$ cells in a concentration-dependent manner. Apoptotic cells show biochemical and morphological changes, with the latter providing the most reliable criteria to assess apoptosis. In our study, morphological changes in cervical cancer cells that were typical of apoptosis were observed under the light and transmission electron microscope. Following treatment with baicalein for $48 \mathrm{~h}$, a variety of morphological changes were noted: shrinkage, rounding, loss of attachment, plasma membrane blebbing, chromatin condensation, mitochondria with vacuoles, karyorrhexis and formation of apoptotic bodies. Quantification of apoptotic rates was performed with Annexin V-FITC/PI staining and flow cytometry, which showed that baicalein treatment significantly increases the proportion of apoptotic cells as compared to the untreated control group $(\mathrm{P}<0.05)$.

An increasing number of studies have shown that proteins of the Bcl-2 family are critical regulators of mitochondrial-mediated apoptosis (e.g., 14). The Bcl-2 family includes the proteins Bcl-2, Bcl-xL, Bak, Bax, Bik and Bid. During the apoptotic 
process, promoters of the Bcl-2 family (Bak, Bax, Bik and Bid) are activated, which causes changes in their conformation, and results in the exposure of the $\mathrm{BH} 3$ domain. Eventually, the release of cytochrome $C$ and other proteins in the mitochondria is involved in the activation of caspase cascades that induce cell apoptosis. Regulation of Bcl-2 and Bax in apoptosis not only depends on their expression levels, but also the ratio between these two proteins. The value of Bax/Bcl-2 is widely used as a criterion to assess whether cells undergo apoptosis following stimulation by diverse signals/agents. An increase in the Bax/ $\mathrm{Bcl}-2$ ratio is commonly accompanied by mitochondrial membrane permeability, resulting in the release of cytochrome $C$ in the mitochondria, which in turn activates downstream caspase cascades and results in the formation of the apoptosome $(15,16)$.

The death-receptor pathway (Fas/FasL/caspase-8) is another signal transduction system inducing apoptosis. The death receptor Fas and its ligand FasL belong to the tumor necrosis factor (TNF) superfamily. FasL binds to Fas on the cell membrane, and then the receptor interacts with the intracellular Fas-associated protein with death domain (FADD). FADD can raise the level of and activate caspase- 8 ; the activated caspase- 8 will then trigger cell apoptosis via two pathways: one is by activating other zymogens of the same family, forming a series of activation cascades, with caspase-3-mediated signaling eventually causing DNA degradation and triggering apoptosis. The second pathway is initiated by the cleavage of the Bid protein in the cytoplasm by activated caspase- 8 . While full-length Bid is localized in the cytosol, truncated Bid translocates to the mitochondria and induces the release of cytochrome $\mathrm{c}$, which sequentially activates caspase-9 and -3 (17). The extrinsic pathway indirectly acts on the intrinsic pathway, and the two pathways synergistically amplify apoptotic signaling, initiating caspase cascades to induce apoptosis.

In this study, baicalein treatment decreased the expression of the Bcl-2 protein, increased the expression of Bax, Fas, FasL and caspase-8, and activated caspase- 3 . We hypothesize that baicalein induced the apoptosis of HeLa cells through two pathways: i) the intracellular mitochondrial pathway, by regulating the expression levels of Bcl-2 and Bax, and increasing the $\mathrm{Bax} / \mathrm{Bcl}-2$ ratio to induce cell apoptosis, and ii) the cellsurface death-receptor pathway, via the upregulation of the Fas and FasL proteins, which can activate caspase-8, and thereby, activate the downstream apoptotic enzyme caspase-3. Via both pathways, the proteolytic enzyme caspase-3, which is an apoptosis executor, may have thus been activated to induce apoptosis.

In summary, HeLa cell proliferation was inhibited by baicalein in a dose-dependent manner. Baicalein induced the apoptosis of HeLa cells, as shown by morphological observation of the cells and flow cytometry. Baicalein most likely induced apoptosis through the mitochondrial and the death-receptor pathways. Additional studies are however required to investigate the molecular mechanisms underlying the anti-cervical cancer property of baicalein in vitro.

\section{References}

1. Di Domenico F, Foppoli C, Coccia R and Perluigi M: Antioxidants in cervical cancer: chemopreventive and chemotherapeutic effects of polyphenols. Biochim Biophys Acta 1822: 737-747, 2012.

2. Dong FY and Jiang RW: Research progress of the natural products against prostate cancer. Chin J Nat Med 9: 81-89, 2011.

3. Mandal SK, Biswas R, Bhattacharyya SS, Paul S, Dutta S, Pathak S and Khuda-Bukhsh AR: Lycopodine from Lycopodium clavatum extract inhibits proliferation of HeLa cells through induction of apoptosis via caspase-3 activation. Eur J Pharmacol 626: 115-112, 2010.

4. Park SE, Yoo HS, Jin CY, Hong SH, Lee YW, Kim BW, Lee SH, Kim WJ, Cho CK and Choi YH: Induction of apoptosis and inhibition of telomerase activity in human lung carcinoma cells by the water extract of Cordyceps militaris. Food Chem Toxicol 47: 1667-1675, 2009.

5. Ling Y, Wang L, Chen Y, Feng F, You QD, Lu N and Guo QL: Baicalein inhibits angiogenesis induced by lipopolysaccharide through TRAF6 mediated toll-like receptor 4 pathway. Biomed Prev Nutr 1: 172-179, 2011.

6. Wang L, Ling Y, Chen Y, Li CL, Feng F, You QD, Lu N and Guo QL: Flavonoid baicalein suppresses adhesion, migration and invasion of MDA-MB-231 human breast cancer cells. Cancer Lett 297: 42-48, 2010.

7. Chen CH, Huang TS, Wong CH, Hong CL, Tsai YH, Liang CC, Lu FJ and Chang WH: Synergistic anti-cancer effect of baicalein and silymarin on human hepatoma HepG2 cells. Food Chem Toxicol 47: 638-644, 2009.

8. Wu B, Li J, Huang D, Wang W, Chen Y, Liao Y, Tang X, Xie H and Tang F: Baicalein mediates inhibition of migration and invasiveness of skin carcinoma through Ezrin in A431 cells. BMC Cancer 11: 527, 2011.

9. Takahashi H, Chen MC, Pham H, Angst E, King JC, Park J, Brovman EY, Ishiguro H, Harris DM, Reber HA, Hines OJ, Gukovskaya AS, Go VL and Eibl G: Baicalein, a component of Scutellaria baicalensis, induces apoptosis by Mcl-1 down-regulation in human pancreatic cancer cells. Biochim Biophys Acta 1813: 1465-1474, 2011.

10. Lee HZ, Leung HW, Lai MY and Wu CH: Baicalein induced cell cycle arrest and apoptosis in human lung squamous carcinoma CH27 cells. Anticancer Res 25: 959-964, 2005.

11. Peng Y, Li QW, Li K, Zhao HW, Han ZS, Li FL, Sun M and Zhang YX: Antitumor activity of baicalein on the mice bearing U14 cervical cancer. Afr J Biotechnol 10: 14169-14176, 2011.

12. Kim HG, Song H, Yoon DH, Song BW, Park SM, Sung GH, Cho JY, Park HI, Choi S, Song WO, Hwang KC and Kim TW: Cordyceps pruinosa extracts induce apoptosis of HeLa cells by a caspase dependent pathway. J Ethnopharmacol 128: 342-351, 2010.

13. Kim R: Recent advances in understanding the cell death pathways activated by anticancer therapy. Cancer 103: 1551-1560, 2005.

14. Choi S and Singh SV: Bax and Bak are required for apoptosis induction by sulforaphane, a cruciferous vegetable-derived cancer chemopreventive agent. Cancer Res 65: 2035-2043, 2005.

15. Whiteman M, Chu SH, Siau JL, Rose P, Sabapathy K, Schantz JT, Cheung NS, Spencer JP and Armstrong JS: The pro-inflammatory oxidant hypochlorous acid induces Bax-dependent mitochondrial permeabilisation and cell death through AIF-/EndoG-dependent pathways. Cell Signal 19: 705-707, 2007.

16. Zinkel S, Gross A and Yang E: BCL2 family in DNA damage and cell cycle control. Cell Death Differ 13: 1351-1359, 2006.

17. Donepudi M, Mac Sweeney A, Briand C and Grütter MG: Insights into the regulatory mechanism for caspase- 8 activation. Mol Cell 11: 543-549, 2003. 